Kalender der Juden

Jahr 5716 (Gemeinjahr von 355 Tagen)

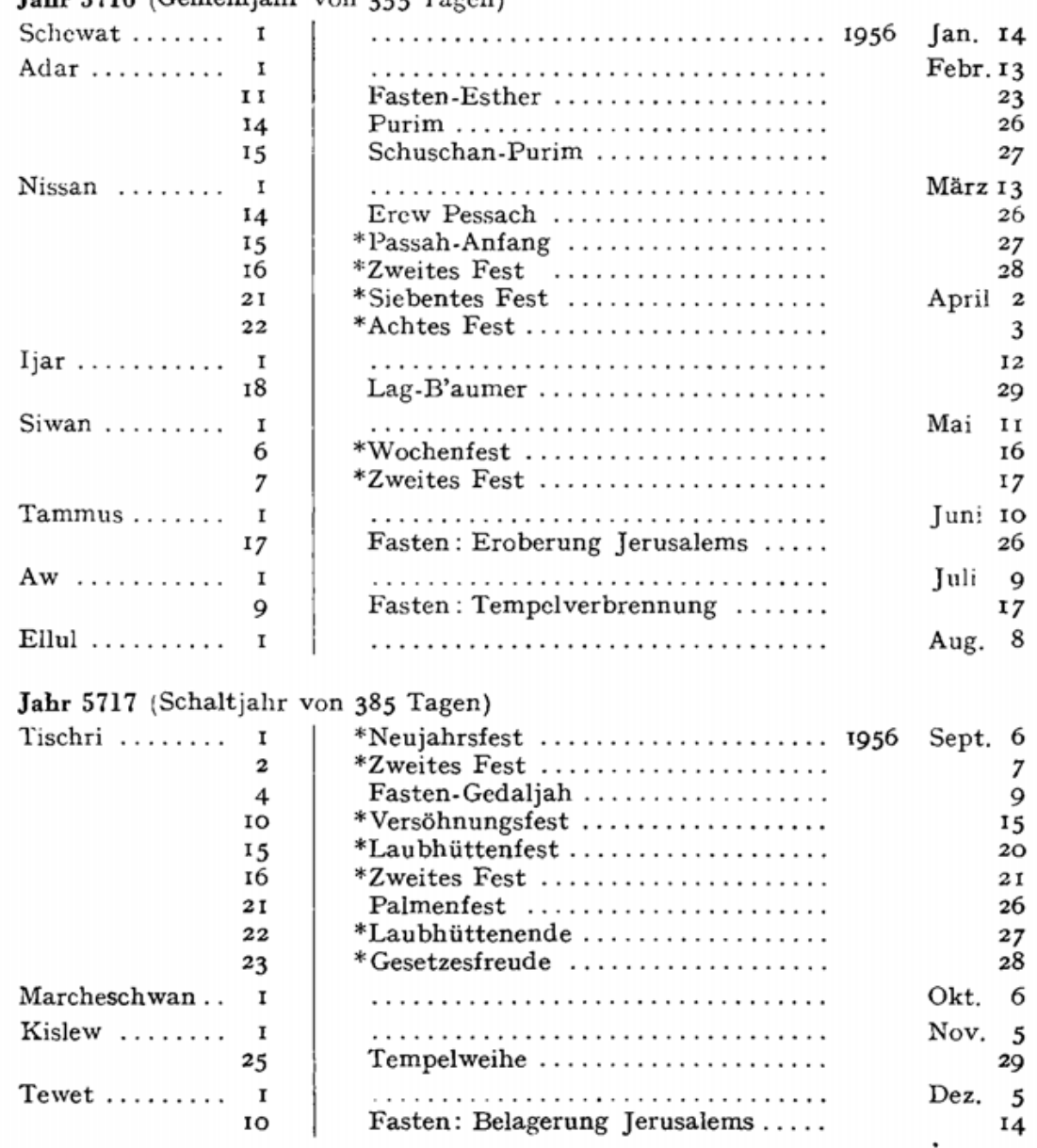

Die mit $\bullet$ bezeichneten Festtage werden streng gefeiert.

\title{
Kalender der Mohammedaner
}

Jahr 1375 (Gemeinjahr von 354 Tagen)

\begin{tabular}{|c|c|c|}
\hline Dschemâdi-el-accher ... & 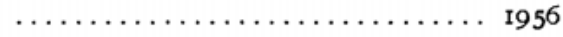 & Jan. I5 \\
\hline Redscheb $\ldots \ldots \ldots \ldots$. & $\ldots \ldots \ldots$ & Febr. 13 \\
\hline Schabân........$\ldots$. & 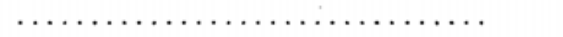 & März I4 \\
\hline Ramadân ............. & 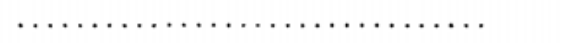 & April I 2 \\
\hline Schewwâl . & $\ldots \ldots \ldots m \cdots \cdots \cdots \cdots$ & Mai I 2 \\
\hline Dsû'l-kade $\ldots \ldots \ldots \ldots$. & 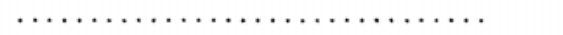 & Juni ro \\
\hline Dsû́l-hedsche $\ldots \ldots \ldots \ldots$ & $\ldots \ldots \ldots \ldots \ldots \ldots \ldots \ldots \ldots \ldots \ldots \ldots$ & Juli ro \\
\hline
\end{tabular}

Jahr 1376 (Schaltjahr von 355 Tagen)

Moharrem ............

Safar .................

Rebî-el-awwel .

…

1956 Aug. 8 .

Sept. 7

Okt. 6

Rebî-el-accher ..........

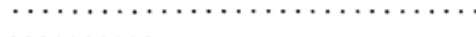

Dschemâdi-el-awwel ...

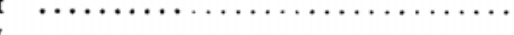

Nov. 5

Dez. 4 